\title{
Reclassification of Lepadogaster candollei based on molecular and meristic evidence with a redefinition of the genus Lepadogaster
}

\author{
F. Almada ${ }^{\text {a,b,c,* }}$, M. Henriques ${ }^{\text {d }}$, A. Levy ${ }^{a}$, A. Pereira ${ }^{\text {a }}$, J. Robalo ${ }^{\text {a }}$, V.C. Almada ${ }^{\text {a }}$ \\ ${ }^{a}$ Unidade de Investigação em Eco-etologia, Instituto Superior de Psicologia Aplicada, Rua do Jardim do Tabaco 34, 1149-041 Lisboa, Portugal \\ ${ }^{\mathrm{b}}$ Instituto de Oceanografia, Faculdade de Ciências da Universidade de Lisboa, Campo Grande, 1749-016 Lisboa, Portugal \\ ${ }^{\mathrm{c}}$ Universidade Lusófona de Humanidades e Tecnologias, Campo Grande 376, 1749-024 Lisboa, Portugal \\ d Parque Natural da Arrábida, Instituto da Conservação da Natureza, Praça da República, 2900 Setúbal, Portugal
}

Received 24 January 2007; revised 11 May 2007; accepted 22 May 2007

Available online 9 June 2007

\section{Introduction}

Several characteristics of the Gobiesocidae, such as the fact that they are small cryptic fishes, could explain the scarcity of studies on these species when compared with other rocky littoral fish families. In the last few years different authors described several new gobiesocid species (Hutchins, 1991; Briggs, 1993, 2001; Hofrichter and Patzner, 1997). Additionally, some ecological and behavioural studies have also been published (Gonçalves et al., 1998; Hofrichter and Patzner, 2000). However, the taxonomy of the subfamily Lepadogastrinae, which is restricted to the Eastern Atlantic, Mediterranean and the Black Sea, is still based on the works of Canestrini (1864), Ninni (1933), and Briggs (1955). Canestrini (1864) divided these fishes in three genera: Gouania, Lepadogaster, and Mirbelia. He distinguished these genera according to the fact that the dorsal and anal fins are separated from the caudal fin by a distinct gap in Mirbelia, while they are broadly connected in Lepadogaster and continuous in Gouania. In other words species such as Lepadogaster candollei (Risso, 1810), Diplecogaster bimaculata (Bonnaterre, 1788) and Opeatogenys gracilis (Canestrini, 1864) were included in the genus Mirbelia.

Chambanaud (1925) and Ninni (1933), based on a continuous or non-continuous fin criterion reclassified the Lepadogastrinae as Gouania or Lepadogaster, respectively, placing Mirbelia as a synonym of Lepadogaster.

\footnotetext{
* Corresponding author. Address: Unidade de Investigação em Ecoetologia, Instituto Superior de Psicologia Aplicada, Rua do Jardim do Tabaco 34, 1149-041 Lisboa, Portugal. Fax: +351 217515590.

E-mail address: frederico.almada@ulusofona.pt (F. Almada).
}

Subsequently Fraser-Brunner (1938) described the genus Diplecogaster and Briggs (1955) maintained the genus Mirbelia as a synonym of Lepadogaster.

Briggs (1955) also provided an extensive revision of the phylogeny and biogeography of the family Gobiesocidae and he clearly admitted that the relationships within the Gobiesocidae subfamilies are more difficult to assess than the relationships among subfamilies. Nelson (2006) did not consider tribes or subfamilies within the gobiesocids.

Traditionally, according to Briggs (1955, 1957, 1986, 1990) and Hofrichter and Patzner (1997), the subfamily Lepadogastrinae comprises six genera and thirteen species: Apletodon dentatus, A. incognitus, A. pellegrini, Diplecogaster bimaculata, $D$. megalops, D. ctenocrypta, Gouania willdenowi, Lecanogaster chrysea, L. candollei, L. lepadogaster (with two subspecies: $L$. l. lepadogaster and L. l. purpurea), L. zebrina, Opeatogenys gracilis and $O$. cadenati. However, the species D. ctenocrypta is based on the description of a single specimen (Briggs, 1955) and should therefore be considered with caution.

Henriques et al. (2002) showed recently that L. zebrina is a population of L. lepadogaster from Madeira Archipelago. These authors also concluded, based on molecular, morphological and ecological data, that $L$. l. lepadogaster and $L$. l. purpurea should be considered two different species and not subspecies as was frequently proposed (e.g. Briggs, 1986). They also noted that L. purpurea and L. lepadogaster form a well supported monophyletic group markedly divergent from $L$. candollei, an observation that had already been advanced by Briggs (1955). Ecological and behavioural differences between $L$. candollei and the remaining Lepadogaster were also stressed by other authors (Gonçalves et al., 1998; Hofrichter and Patzner, 2000). These findings led us to reassess the taxonomic status of L. candollei. 
Table 1

Taxa analysed in this study, geographical origin of the samples and GenBank accession numbers

\begin{tabular}{|c|c|c|c|c|}
\hline $\begin{array}{l}\text { Family (subfamily } \\
\text { sensu Briggs, 1955) }\end{array}$ & Species & $\begin{array}{l}\text { Origin of } \\
\text { samples }\end{array}$ & $\begin{array}{l}12 \mathrm{~S} \\
\text { rDNA }\end{array}$ & $\begin{array}{l}16 \mathrm{~S} \\
\text { rDNA }\end{array}$ \\
\hline & $\begin{array}{l}\text { Lepadogaster } \\
\text { lepadogaster }\end{array}$ & $\begin{array}{l}\text { Mainland } \\
\text { Portugal }\end{array}$ & AY036597 & AF549202 \\
\hline & $\begin{array}{l}\text { Lepadogaster } \\
\text { purpurea }\end{array}$ & $\begin{array}{l}\text { Mainland } \\
\text { Portugal }\end{array}$ & AY036604 & AF549201 \\
\hline & $\begin{array}{l}\text { Lepadogaster } \\
\text { candollei }\end{array}$ & $\begin{array}{l}\text { Mainland } \\
\text { Portugal }\end{array}$ & AY036587 & AF549203 \\
\hline & & Madeira & AF549194 & AF549204 \\
\hline \multicolumn{5}{|l|}{ Gobiesocidae } \\
\hline Lepadogastrinae & $\begin{array}{l}\text { Diplecogaster } \\
\text { bimaculata }\end{array}$ & $\begin{array}{l}\text { Mainland } \\
\text { Portugal }\end{array}$ & AF549197 & AF549205 \\
\hline & $\begin{array}{l}\text { Gouania } \\
\text { willdenowi }\end{array}$ & Croatia & EF363029 & EF363031 \\
\hline & $\begin{array}{l}\text { Opeatogenys } \\
\text { gracilis }\end{array}$ & $\begin{array}{l}\text { Mainland } \\
\text { Portugal }\end{array}$ & AF549196 & AF549206 \\
\hline & $\begin{array}{l}\text { Apletodon } \\
\text { dentatus }\end{array}$ & $\begin{array}{l}\text { Mainland } \\
\text { Portugal }\end{array}$ & AF549200 & AF549207 \\
\hline & $\begin{array}{l}\text { Apletodon } \\
\text { incognitus }\end{array}$ & Azores & AF549198 & AF549208 \\
\hline Aspasminae & $\begin{array}{l}\text { Aspasma } \\
\text { minima }\end{array}$ & $\begin{array}{l}\text { Miya } \\
\text { et al. } \\
(2003)\end{array}$ & NC008130 & NC008130 \\
\hline Gobiesocinae & $\begin{array}{l}\text { Gobiesox } \\
\text { barbatulus }\end{array}$ & Brasil & $\begin{array}{l}\text { AP004453 } \\
\text { EF363030 }\end{array}$ & $\begin{array}{l}\text { AP004453 } \\
\text { EF363032 }\end{array}$ \\
\hline Gobiesocinae & Arcos sp. & $\begin{array}{l}\text { Miya } \\
\text { et al. } \\
(2003)\end{array}$ & AP004452 & AP004452 \\
\hline Blenniidae & $\begin{array}{l}\text { Parablennius } \\
\text { pilicornis }\end{array}$ & $\begin{array}{l}\text { Mainland } \\
\text { Portugal }\end{array}$ & AY098795 & AY098831 \\
\hline
\end{tabular}

\section{Materials and methods}

Samples collected, their geographical origin and GenBank accession numbers are listed in Table 1. Our analysis also included Gobiesox barbatulus, Aspasma minima and one specimen identified as Arcos sp. available in GenBank database (Table 1). Parablennius pilicornis was used as outgroup according to Chen et al. (2003), who placed the Blennioidei as a sister group of the Gobiesocoidei.

DNA was extracted from fin clips preserved in ethanol, using a proteinase K/SDS based protocol (Sambrook et al., 1989). Primer sequences used to amplify a fragment $378 \mathrm{bp}$ long from the $12 \mathrm{~S}$ mitochondrial rDNA (12SFor $5^{\prime}$-AAC TGG GAT TAG ATA CCC CAC- $3^{\prime}$ and 12 SRev $5^{\prime}$-GGG AGA GTG ACG GGC GGT GTG-3'), and a fragment 445 bp long from the mitochondrial 16S rDNA (16SFor 5'-AAG CCT CGC CTG TTT ACC AA-3' and 16SRev 5'-CTG AAC TCA GAT CAC GTA GG-3'), are described in Henriques et al. (2002). PCR conditions followed those described in Almada et al. (2005). The amplifications were performed in a Biometra thermocycler (Biometra, Trio-Thermblock, Göttingen, Germany) and were conducted as follows: 4 min at $94{ }^{\circ} \mathrm{C}$ and 30 cycles of: $\left[94{ }^{\circ} \mathrm{C}(1 \mathrm{~min}), 55^{\circ} \mathrm{C}(1 \mathrm{~min})\right.$ and $\left.72{ }^{\circ} \mathrm{C}(1 \mathrm{~min})\right], 10 \mathrm{~min}$ at $72{ }^{\circ} \mathrm{C}$ for both fragments.

All samples were sequenced in both directions and sequencing reactions were performed by Macrogen Inc.
(Seoul, Republic of Korea) in a MJ research PTC-225 Peltier Thermal Cycler using a ABI PRISM BigDyeTM Terminator Cycle Sequencing Kits with AmpliTaq DNA polymerase (Applied Biosystems), following the protocol supplied by the manufacturer.

Sequences were aligned with Clustal X 1.81 (Thompson et al., 1994) and were analysed with maximum parsimony (MP), minimum evolution (neighbour-joining) (ME) and maximum likelihood (ML) methods available in PAUP 4.0 (Swofford, 1998). Bootstrapping was used to access robustness of the nodes in the trees with 1000 replicates. The molecular evolution model used for the ME and ML tree was selected according to the results of Modeltest 3.7 (Posada and Crandall, 1998) with the AIC criterion.

Dolphin et al. (2000) showed that even when ILD (Farris et al., 1995) tests reveal significant differences between two fragments it is frequently preferable to analyse them together. Thus the two fragments were combined in a single data set.

We tested the monophyly of the genus Lepadogaster and the subfamily Lepadogastrinae by comparing unconstrained trees and topologies constrained such that (1) L. candollei was forced to be the sister species of the $L$. purpurea-L. lepadogaster clade, and (2) the Lepadogastrinae were forced to be monophyletic. Unconstrained and constrained tree were obtained using MP, ME, and ML methods, and compared using a Kishino and Hasegawa test (1989), in the case of MP topologies, and using the Shimodaira and Hasegawa (1999) tests for ME and ML trees. The latter test adjusts the expected distribution of log likelihood differences when comparing a posteriori hypotheses or multiple topologies (Buckley et al., 2001; Felsenstein, 2004). Both tests were implemented in PAUP v.4.0b10 (Swofford, 1998).

Bayesian analysis was performed using MCMC as implemented in Mr. Bayes 3.1 (Ronquist and Huelsenbeck, 2003), with four independent runs of four Metropolis-coupled chains of 2,000,000 generations each, to estimate the posterior probability distribution. Data were partitioned by ribosomal region, and independent $\mathrm{GTR}+\mathrm{G}+\mathrm{I}$ assumed for each partition. Topologies were sampled every 100 generations, and a majority-rule consensus tree was estimated after discarding the first 1000 sampled generations.

Maximum likelihood analysis used likelihood setting estimated by Modeltest 3.7 (Posada and Crandall, 1998), a heuristic search algorithm with TBR branch swapping and 100 bootstrap replicates.

The meristic variables used in this study, follow those considered by Briggs $(1955,1957)$ with some additions (Hofrichter and Patzner, 1997; Henriques et al., 2002) are: number of dorsal rays; number of anal rays; number of pectoral rays; number of caudal rays; number of papillae rows in the anterior region of the pelvic disc; number of papillae rows in posterior region of the pelvic disc; presence/absence of papillae lateral rows; presence/absence of central papillae in anterior region of the pelvic disc; presence/absence of teeth dimorphism; number of rakers; presence/absence of anal papillae; united/separated dorsalanal-caudal fins; presence/absence of opercular spine; pres- 
ence/absence of sexual dimorphism; presence/absence of fleshy pad on lower pectoral base; gills three and onehalf/gills three; presence/absence of double disc; maximum standard length; presence/absence of gill membrane attached to isthmus; presence/absence of elongated nostril; presence/absence head-papillae; number of vertebrae. A cluster analysis (UPGMA) of meristic characters was performed based on their percent disagreement. Statistical treatment was performed with the software package STATISTICA 5.5 (StatSoft $^{\odot}$, Inc.).

\section{Results}

When plotting transitions and transversions over patristic distances (plot not shown) transitional saturation was noticeable for distances greater than $22 \%$. The genetic distance among congeneric species was less than $4 \%$ (p-distance) with the exception of $L$. candollei, which showed a genetic distance of $13.9-15.0 \%$ from the remaining species of the genus Lepadogaster, a range of distances that is of the same order as other intergeneric distances shown in Table 2.

Table 2

Percent genetic distance ( $p$-distance) between the DNA sequences of a combined fragment of the 12S and 16S rDNA

\begin{tabular}{|c|c|c|c|c|c|c|c|c|c|c|c|c|c|}
\hline & A.d. & A.i. & L.p. & L.l. & G.w. & L.c.cP & L.c. Mad & A.m. & O.g. & D.b. & G.b. & A. sp. & P.p. \\
\hline A. dentatus & - & 2.78 & 21.03 & 22.43 & 21.52 & 18.72 & 19.08 & 21.36 & 19.70 & 19.57 & 23.25 & 20.88 & 25.13 \\
\hline A. incognitus & & - & 20.65 & 21.80 & 22.54 & 19.99 & 20.22 & 22.24 & 20.72 & 20.59 & 23.11 & 20.37 & 24.86 \\
\hline L. purpurea & & & - & 3.26 & 14.95 & 13.86 & 14.35 & 18.66 & 15.50 & 14.48 & 18.87 & 18.19 & 23.30 \\
\hline L. lepadogaster & & & & - & 14.18 & 14.85 & 14.97 & 17.78 & 16.24 & 15.11 & 20.22 & 17.66 & 23.18 \\
\hline G. willdenowi & & & & & - & 15.27 & 15.25 & 19.23 & 16.25 & 15.79 & 20.72 & 18.42 & 24.15 \\
\hline L. candollei $\mathrm{cP}$ & & & & & & - & 1.38 & 15.87 & 13.01 & 13.27 & 18.53 & 17.98 & 22.38 \\
\hline L. candollei Mad & & & & & & & - & 16.12 & 13.38 & 13.76 & 19.02 & 18.48 & 22.61 \\
\hline A. minima & & & & & & & & - & 18.94 & 18.55 & 22.69 & 19.99 & 23.86 \\
\hline O. gracilis & & & & & & & & & - & 14.66 & 20.92 & 18.62 & 23.24 \\
\hline D. bimaculata & & & & & & & & & & - & 18.89 & 16.97 & 22.57 \\
\hline G. barbatulus & & & & & & & & & & & - & 19.45 & 24.18 \\
\hline $\operatorname{Arcos}$ sp. & & & & & & & & & & & & - & 17.99 \\
\hline P. pilicornis & & & & & & & & & & & & & - \\
\hline
\end{tabular}

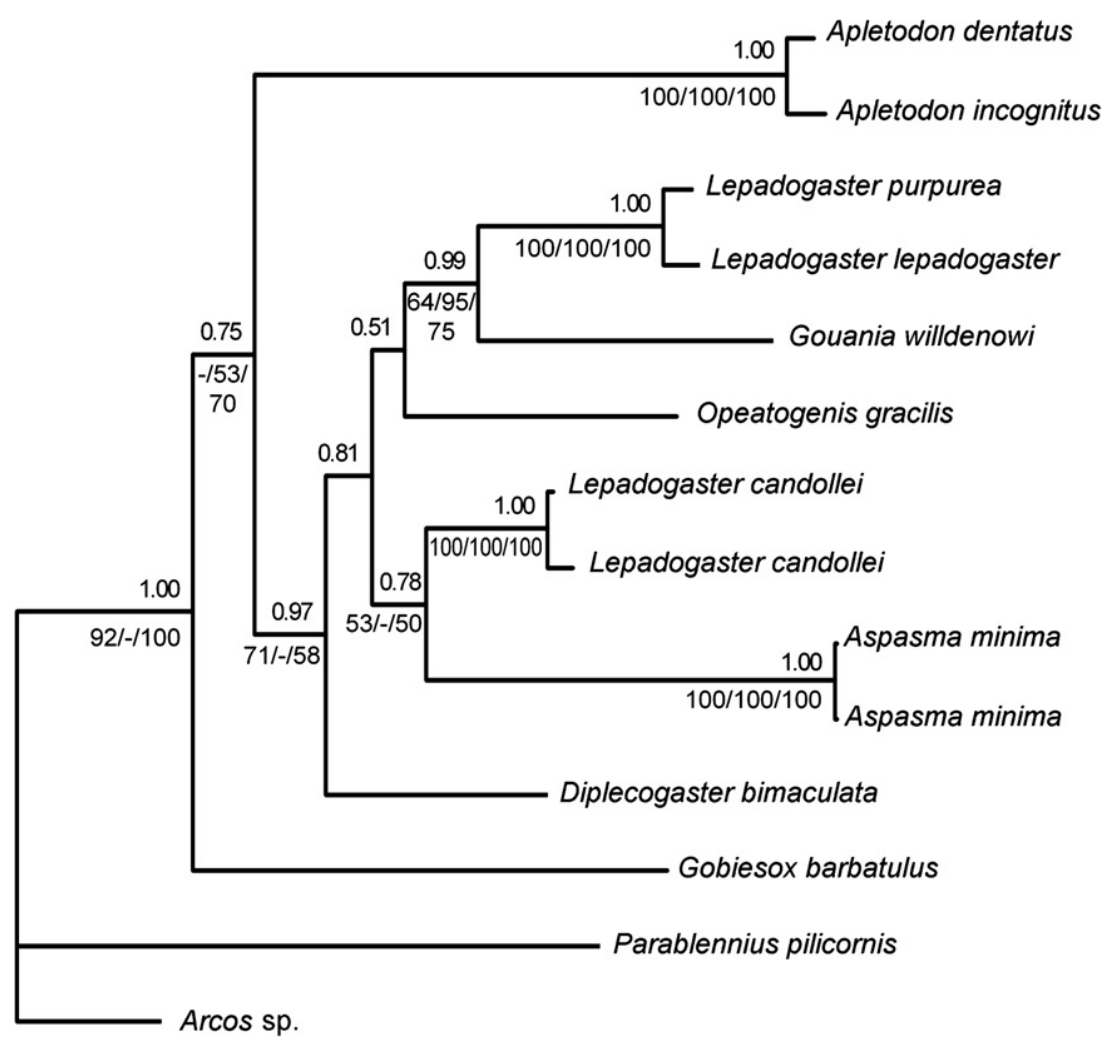

Fig. 1. Phylogenetic relationships of the Atlanto-Mediterranean gobiesocids (Lepadogastrinae) obtained from molecular data. Clingfishes from other subfamilies are also shown (A. minima-Aspasminae; G. barbatulus, Arcos sp.-Gobiesocinae). Parablennius pilicornis (Blenniidae) was used as outgroup. Bayesian posterior probabilities and MP $(\mathrm{CI}=0.63, \mathrm{RI}=0.59, \mathrm{TL}=906), \mathrm{ME}$ and $\mathrm{ML}$ bootstrap support are shown above and below each node, respectively. Although with a lower phylogenetic resolution, MP, ME, and ML inference methods never supported a different topology when compared with Bayesian trees. 
Concerning the phylogenetic analysis (Fig. 1), all inference methods recovered the following features:

(1) The traditionally accepted genus Lepadogaster is polyphyletic since L. lepadogaster and L. purpurea were never recovered forming a monophyletic clade with $L$. candollei. Instead L. lepadogaster and L. purpurea form a clade that is sister to G. willdenowi. When we constrained trees to place $L$. candollei to be sister to the clade $L$. lepadogaster/L. purpurea the MP tree was longer ( 918 versus 906 steps) than the unconstrained tree although the difference was non significant $(\mathrm{K}-\mathrm{H}$ test $t=1.635 ; \mathrm{SD}=7.341$ and $p=0.103$ ). Topologies unconstrained by a monophyletic Lepadogaster genus had significantly better likelihoods than constrained topologies (Shimodaira-Hasegawa one-tailed tests for ME and ML, respectively; difference in $-\ln L=10.919, p=0.042$; difference in $-\ln L=10.635, p=0.027$ );

(2) If the hypothesis that the subfamilies Aspasminae and Lepadogastrinae are not monophyletic is confirmed by a broader taxonomic analysis, it has interesting biogeographic implications. However, these results must be taken with caution as neither the $\mathrm{K}-\mathrm{H}$ test nor the $\mathrm{S}-\mathrm{H}$ tests for ME and ML yielded statistically significant differences $(\mathrm{K}-\mathrm{H}$ test $t=1.306, \mathrm{SD}=8.423$ and $p=0.192 ; \mathrm{S}-\mathrm{H}$ test $\mathrm{ME}$ diff. $\quad-\ln L=3.243, \quad p=0.216 ; \quad$ difference in $-\ln L=6.342, p=0.027$ );

(3) The subfamily Gobiesocinae is also a problematic taxon. While Gobiesox was recovered as being sister to the Lepadogastrinae plus Aspasma, Arcos, which also belongs to the Gobiesocinae, never formed a clade with Gobiesox, being recovered in a very basal position;
(4) The relationships of $L$. candollei with other taxa are unresolved although moderate support exists for a sister relationship with Aspasma. A grouping corresponding to Mirbelia as defined by Canestrini (1864) including $L$. candollei and species of the genera Diplecogaster and Opeatogenys was never recovered.

The analysis of the meristic data (Fig. 2) independently supports the similarity between $L$. lepadogaster, $L$. purpurea, and $G$. willdenowi and the separation of $L$. candollei from this group. It even suggests some morphological similarities between $L$. candollei, D. bimaculata, and $O$. gracilis, again with $A$. minima included in the same group. In contrast to the phylogenetic results, cluster analysis grouped the genera Gobiesox and Arcos, placing the Lepadogastrinae plus the genus Aspasma in a distinct cluster.

\section{Discussion}

A major conclusion emerging from the results presented above is the need to remove $L$. candollei from the genus Lepadogaster. Canestrini (1864) had already felt the need to place $L$. candollei in a genus (Mirbelia) distinct from Lepadogaster. In turn Briggs (1955), in his detailed revision, although placing $L$. candollei in Lepadogaster had noted that: "L. candollei is well separated from the other three forms (of Lepadogaster) which are very closely related to each other". These three species included $L$. zebrina which was subsequently shown to be a synonym of Lepadogaster lepadogaster by Henriques et al. (2002). Gonçalves et al. (1998) and Hofrichter and Patzner (2000) showed that $L$. candollei differs very markedly both

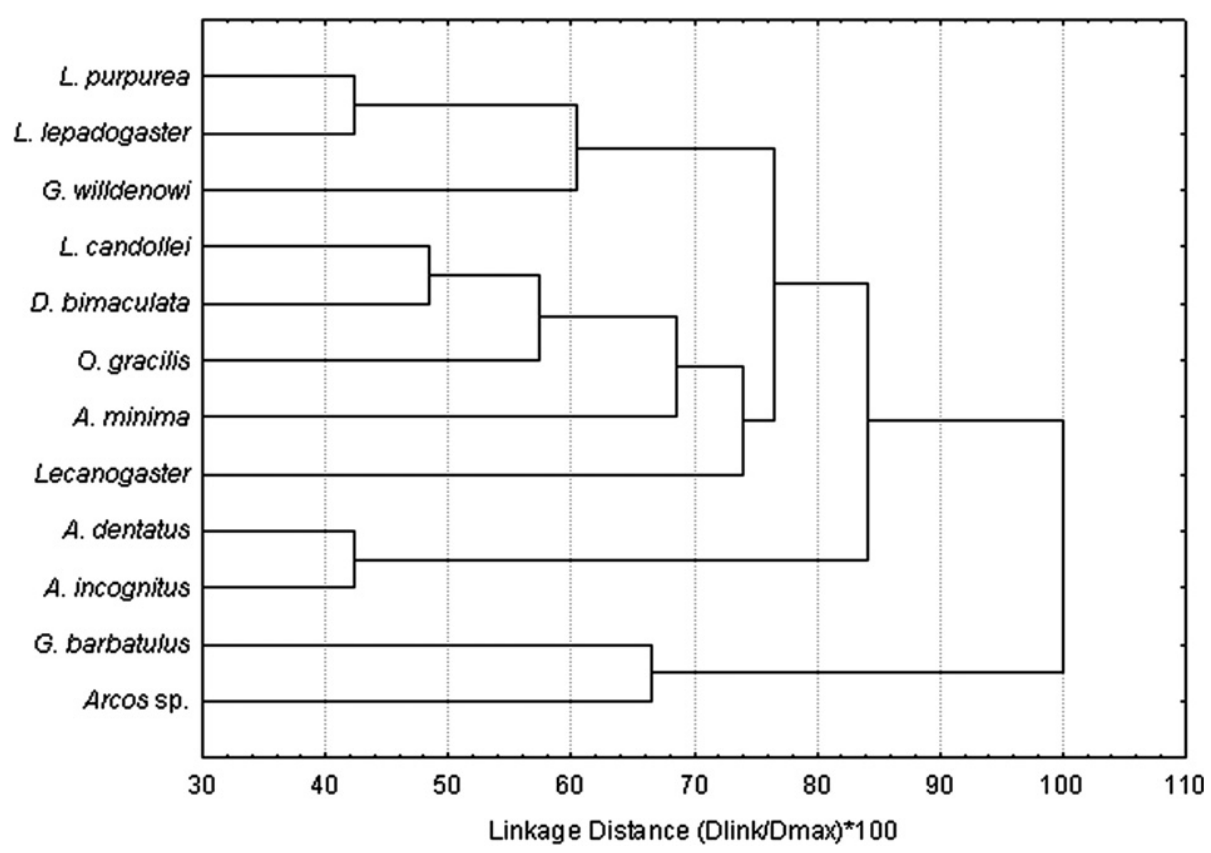

Fig. 2. Cluster analysis obtained from meristic data (UPGMA with percent disagreement distances). 
in ecology and behaviour from the remaining species of Lepadogaster. While these are very cryptic species that spend most of the time hidden under boulders, and rarely swim in the water column, $L$. candollei is a more active fish that swims frequently and forages openly out of shelter. It also differs in agonistic behaviour from the other Lepadogaster.

Thus our analyses of molecular and meristic data are in agreement with the views of previous workers. Therefore, we propose that the genus Lepadogaster must be redefined to include only the species L. lepadogaster (Bonaterre, 1788 ) and L. purpurea (Bonaterre, 1788). Removing L. candollei from the genus Lepadogaster begs the question of its generic position. Lepadogaster candollei did not occur in any well supported clade that would suggest its inclusion in any particular genus.

Our analysis included small numbers of individuals of each genus and lacked representatives of Lecanogaster, a tropical African monospecific genus. Therefore the molecular data do not allow the resolution of the relationships of L. candollei except for the inadequacy of keeping it in Lepadogaster. The analysis of the meristic data that already includes Lecanogaster also failed to point to the inclusion of $L$. candollei in any other genus, while suggesting a possible association with Diplecogaster and Opeatogenys.

Canestrini (1864) included $L$. candollei with D. bimaculata and $O$. gracilis in the genus Mirbelia. We propose that for the time being the genus Mirbelia should be revalidated and redefined to include only the species Mirbelia candollei (Risso, 1810). This proposal has the advantage of calling attention to the need to separate $M$. candollei from Lepadogaster and to its distinctiveness from other clingfishes.

The genus Lepadogaster, excluding L. candollei, should be redefined as follows: median fins united to the caudal fin; long dorsal fin with 16-21 rays; 20-23 pectoral fin rays; anterior nostril with an appendage on its posterior margin with the form of a large cirrus extending back to the posterior margin of the eye and 3-6 rows of papillae in the posterior region of the sucking disc. The monospecific genus Mirbelia is characterized by the following diagnostic traits: dorsal, caudal, and anal fins clearly separated; dorsal fin long, with 13-16 rays; pectoral fins with 26-29 rays; an appendage on the posterior margin of the anterior nostril in the form of a very small dermal flap; and, the posterior region of the sucking disc with 7-9 rows of papilae.

It could be argued that because there are some signs of saturation of the molecular data our conclusions may be weak. Transitional saturation was however noticeable at distances of about $22 \%$ while the conclusions presented above are based on distances well below that value. It is urgent to perform a comprehensive phylogenetic analysis of the family Gobiesocidae with a broader taxon sampling and additional molecular data and proper mapping of the morphological characters on the new phylogeny. Indeed the present study while not intended to address this broader issue serves as a warning that the Gobiesocidae subfamilies, as currently viewed, need to be re-evaluated.

\section{Acknowledgments}

The authors thank to Marcelo Kovačić and Mauricio Hostim Silva for providing some of the samples and to Thomas Guillemaud (USVE, INRA), Leonor Cancela and her team (UA-UCTRA), and to Dr. Rui Malhó and his team (FCUL, DBV) for their help. This study was funded by Fundação para a Ciência e Tecnologia as part of the Plurianual Program UI\&D 331/94. F.A. was supported by an FCT grant PRAXIS XXI/BD/11178/97 and A.L. was supported by an FCT Grant (SFRH/BPD/ 18067/2004).

\section{References}

Almada, F., Almada, V., Guillemaud, T., Wirtz, P., 2005. Phylogenetic relationships of the north-eastern Atlantic and Mediterranean blenniids. Biol. J. Lin. Soc. 86, 283-295.

Bonnaterre, J.P., 1788. Tableau encyclopédique et méthodique des trois règnes de la nature. Ichthyologie, Paris.

Briggs, J.C., 1955. A monograph of the clingfishes (Order Xenopterygii). Stanford Ichth. Bull. 6, 33-39.

Briggs, J.C., 1957. A new genus and two new species of eastern Atlantic clingfishes. Copeia 3, 204-208.

Briggs, J.C., 1986. Gobiesocidae. In: Whitehead, P.J.P., Bauchot, M.-L., Hureau, J.-C., Nielson, J., Tortonese, E. (Eds.), Fishes of the Northeastern Atlantic and the Mediterranean. UNESCO, Paris, pp. 13511359.

Briggs, J.C., 1990. Gobiesocidae. In: Quéro, J.C., Hureau, J.C., Karrer, C., Post, A., Saldanha, L. (Eds.), Check-list of the Fishes of the Eastern Tropical Atlantic. UNESCO, SEI, JNICT, Lisboa, pp. 476-478.

Briggs, J.C., 1993. New genus and species of clingfish (Gobiesocidae) from southern Australia. Copeia 1, 196-199.

Briggs, J.C., 2001. New clingfish (Gobiesocidae) from Isla Grande, Colombia. Copeia 3, 745-746

Buckley, T.R., Simon, C., Shimodaira, H., Chambers, G.K., 2001. Evaluating hypotheses on the origin and evolution of the New Zealand alpine cicadas (maoricicada) using multiple-comparison tests of tree topology. Mol. Biol. Evol. 18, 223-234.

Canestrini, G., 1864. Studi sui Lepadogaster del Mediterraneo. Arch. Zool. Anat. Fisiol. 3, 177-196.

Chambanaud, M.P., 1925. Lepadogaster (Mirbelia) bimaculatus Penn., Microcephalus Brook et Pellegrini, Nov. Sp. (Pisces Gobiesocidae). Bull. Mus. Hist. Nat. 31, 283-287.

Chen, W.J., Bonillo, C., Lecointre, G., 2003. Repeatability of clades as a criterion of reliability: a case study for molecular phylogeny of Acanthomorpha (Teleostei) with large numbers of taxa. Mol. Phylogenet. Evol. 26, 262-288.

Dolphin, K., Belshaw, R., Orme, C.D.L., Quicke, D.L.J., 2000. Noise and incongruence: interpreting results of the incongruence length difference test. Mol. Phylogenet. Evol. 17 (3), 401-406.

Farris, J.S., Källersjö, M., Kluge, A.G., Bult, C., 1995. Testing significance of incongruence. Cladistics 10, 315-319.

Felsenstein, J., 2004. Inferring Phylogenies. Sinauer Associates Inc., Sunderland.

Fraser-Brunner, A., 1938. Notes on the classification of certain British fishes. Ann. Mag. Nat. Hist. 11, 410-416.

Gonçalves, D.M., Gonçalves, E.J., Almada, V.C., Almeida, S.P., 1998. Comparative behaviour of two species of Lepadogaster (Pisces: Gobiesocidae) living at different depths. J. Fish Biol. 53, 447-450.

Henriques, M., Lourenço, R., Almada, F., Calado, G., Gonçalves, D., Guillemaud, T., Cancela, M.L., Almada, V.C., 2002. A revision of the status of Lepadogaster lepadogaster (Pisces: Gobiesocidae) sympatric sub-species or a long misunderstood blend of species?. Biol. J. Lin. Soc. $76327-338$. 
Hofrichter, R., Patzner, R.A., 1997. A new species of Apletodon from the Mediterranean Sea and the eastern Atlantic with notes on the differentiation between Apletodon and Diplecogaster species (Pisces: Teleostei: Gobiesociformes: Gobiesocidae). Senckenberg. Biol. 77 (1), 15-22.

Hofrichter, R., Patzner, R.A., 2000. Habitat and microhabitat of Mediterranean clingfishes (Teleostei: Gobiesociformes: Gobiesocidae). Mar. Ecol. 21 (1), 41-53.

Hutchins, J.B., 1991. Description of a new deepwater clingfish (Gobiesocidae) from New South Wales. Rec. W.A. Mus. 15 (2), 463-468.

Kishino, H., Hasegawa, M., 1989. Evaluation of the maximumlikelihood estimate of the evolutionary tree topologies from DNAsequence data, and the branching order in Hominoidea. J. Mol. Evol. 29, 170-179.

Miya, M., Takeshima, H., Endo, H., Ishiguro, N.B., Inoue, J.G., Mukai, T., Satoh, T.P., Yamaguchi, M., Kawaguchi, A., Mabuchi, K., Shirai, S.M., Nishida, M., 2003. Major patterns of higher teleostean phylogenies: a new perspective based on 100 complete mitochondrial DNA sequences. Mol. Phylogenet. Evol. 26 (1), 121-138.

Nelson, J.S., 2006. Fishes of the World, fourth ed. John Wiley \& Sons Inc., New Jersey.
Ninni, A.P., 1933. Primo contributo allo studio dei 'Lepadogaster'. Notas y Resumes Instituto Español de Oceonografia 65, 1-34.

Posada, D., Crandall, K.A., 1998. Modeltest: testing the model of DNA substitution (v.3.7). Bioinformatics 14, 817-818.

Risso, A., 1810. Ichthyologie de Nice, ou histoire naturelle des poissons du département des Alpes Maritimes. Ichthyologie. F. Schoell, Paris.

Ronquist, F., Huelsenbeck, J.P., 2003. MRBAYES 3: Bayesian phylogenetic inference under mixed models. Bioinformatics 19, 1572-1574.

Sambrook, J., Fritsch, E.F., Maniatis, T., 1989. Molecular Cloning: a Laboratory Manual, second ed. Cold Spring Harbor Laboratory Press, Cold Spring Harbor, New York.

Shimodaira, H., Hasegawa, M., 1999. Multiple comparisons of loglikelihoods with applications to phylogenetic inference. Mol. Biol. Evol. 16, 1114-1116.

Swofford, D.L., 1998. PAUP*: Phylogenetic Analysis Using Parsimony (* and Other Methods) (v. 4.0). Sinauer Associated, Sunderland, MA.

Thompson, J.D., Higgins, D.G., Gibson, T.J., 1994. Clustal W: improving the sensitivity of progressive multiple sequence alignment through sequence weighting, position-specific gap penalties and weight matrix choice. Nucleic Acids Res. 22, 4673-4680. 